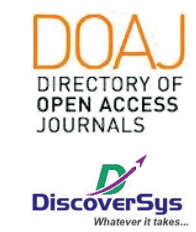

Published by DiscoverSys

\section{The correlation of anxiety disorders and tension-type headache among medical students of Udayana University}

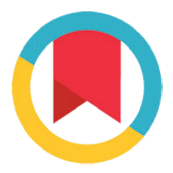

CrossMark

\author{
Christine Kathy Putri Sari, ${ }^{1 *}$ Sri Yenni Trisnawati GS, ${ }^{2}$ Ida Ayu Sri Wijayanti, ${ }^{2}$ \\ AA Bagus Ngurah Nuartha
}

\title{
ABSTRACT
}

Introduction: A Tension-type headache (TTH) is a headache that is commonly happened in almost two-thirds of the world population, especially in medical students. Psychosocial factors, such as anxiety, is often contributed to the incidence of a tension-type headache.

Method: The research was using a cross sectional design study to prove the correlation of anxiety disorders and TTH in medical students. Samples were collected by a consecutive method from medical students on second semester, fourth semester, and sixth semesters of Udayana University study year 2017/2018. TTH was diagnosed based on Konsensus Nasional IV PERDOSSI 2013 and anxiety was scored by
Hamilton Rating Scale for Anxiety (HARS). Lambda test was used to prove the correlation between anxiety disorders and TTH.

Result: There were 300 subjects with dominant age was between $19-20$ years old (60.7\%) and mostly woman (56.7\%). The proportion of TTH was $85.3 \%$ while anxiety disorders were $66.7 \%$. The incidence of TTH was found more commonly happened in a subject with anxiety disorders $(94.5 \%)$ and statistically significant $(p=0.001)$ with weak correlation $(r=0.153)$.

Conclusion: These data show a correlation of anxiety disorders and TTH with weak correlation.
${ }^{1}$ Medical Education Program ${ }^{2}$ Neurology Department/SMF of RSUP Sanglah

Medical Faculty of Udayana University
*Correspondence to: Christine Kathy Putri Sari, Medical Education Program, Medical Faculty of Udayana University christine.kathy13@gmail.com

Received: 2019-02-02 Accepted: 2019-03-07 Published: 2019-08-01

Keywords: anxiety disorders, medical student, tension-type headache Cite This Article: Sari, C.K.P., GS, S.Y.T., Wijayanti, I.A.S., Nuartha, A.A.B.N. 2019. The correlation of anxiety disorders and tension-type headache among medical students of Udayana University. Intisari Sains Medis 10(2): 210-214. D0I: 10.15562/ism.v10i2.407

\section{INTRODUCTION}

A headache is a pain in the head that occurs due to a nervous system disorder caused by various factors. According to Lindsay et al. (2004) in Viona (2012), headache is an uncomfortable pain that is located between the orbital and a head which is sensitive to pain. Headache is the most common nervous system disorder. Based on the International Headache Society (IHS), a headache can be divided into three classifications, i.e., primary headaches, secondary headaches and cranial headaches and other facial pain. As an example of a primary headache is a tension-type headache. ${ }^{1,2}$

A tension-type headache (TTH) is a disease of a primary headache that is often experienced by nearly two-thirds of the world's population. ${ }^{3}$ This headache can occur in both men and women. But it is more common in women with a percentage of $88 \%$ and $69 \%$ in men. ${ }^{4}$ Generally, in any country, TTH has a high prevalence and risk factors.

Although a tension-type headache is the most common disease, research is still rare for this in Indonesia. TTH can be accompanied by other complaints, one of them is psychiatric disorders. Psychiatric disorders, such as anxiety, have a high prevalence of patients with a primary headache. ${ }^{5}$ About $28.1 \%$ of patients with anxiety disorders experience somatic symptoms of TTH. From the research studies conducted by Wei et al. (2016), it was found that $13.7 \%$ of patients with major complaints of TTH experienced anxiety disorders. For patients who experience anxiety disorders, in general also experience mild to a moderate headache. ${ }^{6}$

The presence of comorbid anxiety disorders can increase the duration and frequency of the appearance of TTH. In the International Classification of Headache Disorders, 2nd Edition (ICHD-II), TTH with anxiety disorders is a new diagnosis of a secondary headache. According to Ramezani et al. (2015), the prevalence of anxiety disorders (52.5\%) is quite high in patients with TTH. ${ }^{5}$ However, the relationship of TTH with specific anxiety disorders is not yet known surely because the related research is relatively rare. Based on the background, the author feels need to examine more deeply about the correlation of tension-type headaches with anxiety disorders.

\section{METHOD}

The research was using a cross sectional design study to prove the correlation of anxiety disorders and TTH in medical students. There were 300 samples collected by a consecutive method from 
medical students on second semester, fourth semester, and sixth semesters of Udayana University study year 2017/2018. Inclusion criteria are age 17-22 years old, male or female; subjects are willing to be a respondent. Exclusion criteria were subjects who refused to participate; subjects had sleep disorders, a history of taking drugs (anxious trigger substances), a high-stress level, head trauma, intracranial lesion, and a history of seizures.

The independent variable in this study was anxiety disorders, the dependent variable in this study was a tension-type headache (TTH), and the confounding variables in this study were age, gender, and semester level of the subjects. A headache diagnosed based on the 2013 PERDOSSI IV National Consensus, the presence or absence of TTH will be described with the nominal variable used in the questionnaire. Anxiety disorders were assessed by the Hamilton Rating Scale for Anxiety (HARS) using a nominal variable with an interpretation of the total score $\leq 6$ categorized as no anxiety disorder and $\geq 7$ categorized as an anxiety disorder.

The selection of respondents began with interviews to obtain inclusion and exclusion criteria. Respondents who fulfill the inclusion and exclusion criteria will be contacted and asked for approval by signing informed consent. Patients were given two questionnaires, a questionnaire for TTH through questions with criteria based on National Consensus IV PERDOSSI and a validated Hamilton Anxiety Rating Scale (HAM-A) questionnaire to assess anxiety disorders.

The data then is processed, presented in table form and the analysis of results will be carried out. Univariate analysis was conducted to describe the characteristics of respondents in the study. Bivariate analysis with Lambda correlation test was used to determine the correlation between anxiety disorders and TTH that were nominal in scale. If $\mathrm{p}$-value $<0.05$, it means that there is a correlation between anxiety disorders and TTH. Data is processed with the help of the SPSS 20.0 for Windows computer program.

\section{RESULT}

This research uses primary data by retrieving the data through a questionnaire that conducted in April to July 2018 and directed to medical students in $2^{\text {nd }}, 4^{\text {th }}$, and $6^{\text {th }}$ semester of Udayana University study year 2017/2018. Total research respondents were 300 people after fulfilling the inclusion and exclusion criteria. Characteristics of respondents between groups are described in Table 1 .

Table 2 shows the characteristics of tensiontype headaches for age differences. The highest proportion of TTH is in the age range of 21-22 years old, i.e., 67 out of 73 people (91.8\%). Table 3 shows the characteristics of TTH for sex differences. The highest proportion of TTH is in male, which is 113 of 130 people $(86.9 \%)$. Table 4 shows the characteristics of TTH for semester level differences. The highest proportion of TTH is in the 6th semester, which is 90 out of 100 people (90\%).

The Lambda correlation test was used to prove the relation of anxiety disorders with a tension-type headache. There were 189 (94.5\%) respondents who experienced anxiety disorders also had TTH. After the Lambda correlation test analyzed the data, the value of $r=0.153$ was obtained with a significance value of $p=0.001$. The results of this study are this value indicates an association between anxiety disorders and TTH, but with the strength of weak correlation (Table 5).

\section{DISCUSSION}

The highest proportion of dominant age was 19-20 years old with 182 people (60.7\%). Because most students in $2^{\text {nd }}, 4^{\text {th }}$ and $6^{\text {th }}$ semesters were born in the range of 1997 and 1998 that listed on the respondent's ID card. Meanwhile, the subjects in this study mostly woman. Because, on average the $2^{\text {nd }}, 4^{\text {th }}$ and $6^{\text {th }}$ semester of medical students from the Medical Faculty of Udayana University were more dominated by women.

At the level of the semester, the proportions were designed equally, i.e., 100 people $(33.3 \%)$ at each semester so that the results of the correlation of anxiety disorders with TTH can be compared in a balanced manner between respondents in $2^{\text {nd }}, 4^{\text {th }}$ and $6^{\text {th }}$ semester. The research subjects who experienced anxiety disorders were 200 people (66.7\%). These results are by the results of several other studies. The study by Tabalipa et al. (2015) found the prevalence of anxiety disorders in medical students in Brazil at 35.5\% (95\% CI: 29.7-41.3); Ibrahim et al. (2014) obtained 164 people (43.9\%) medical students in Egypt experienced anxiety disorders. ${ }^{8}$

In this study, subjects who experienced a tension-type headache were 256 people (85.3\%). These results are by several previous studies, as in the study by Yadav (2016) which found the prevalence of TTH by $68 \%$ in subjects aged $18-25$ years old. In a study by Al-Jabry et al. (2015), 58\% of medical students in Saudi Arabia had a history of TTH. ${ }^{9}$

The case of a tension-type headache in this study was obtained more in the research subjects aged 21-22 years old with 67 out of 73 people (91.8\%). A study by Al-Jabry et al. (2015), found the average age of the research subjects, i.e., $21.14 \pm 0.49 .{ }^{9}$ According to Lyngberg et al. (2005) in an article 
Table 1 Characteristics of Research Subjects

\begin{tabular}{lcc}
\hline Variable & Frequency & $\%$ \\
\hline Age & 45 & 15 \\
$17-18$ years old & 182 & 60,7 \\
$19-20$ years old & 73 & 24,3 \\
$21-22$ years old & & \\
Sex & 130 & 43,3 \\
Male & 170 & 56,7 \\
Female & & 33,3 \\
Level of Semester & 100 & 33,3 \\
$2^{\text {nd }}$ semester & 100 & 33,3 \\
$4^{\text {th }}$ semester & 100 & \\
$6^{\text {th }}$ semester & & 66,7 \\
Anxious disorders & 200 & 33,3 \\
Yes & 100 & 85,3 \\
No & & 14,7 \\
Tension-type headache & 256 & \\
Yes & 44 & \\
No & &
\end{tabular}

Table 2 Characteristics of Subjects with Age-Based of Tension-Type Head (TTH)

\begin{tabular}{lccc}
\hline & \multicolumn{2}{c}{ Tension-Type Head } & \\
\cline { 2 - 3 } Age & Yes & No & Total \\
\hline $17-18$ years old & $37(82,2 \%)$ & $8(17,8 \%)$ & 45 \\
$19-20$ years old & $152(83,5 \%)$ & $30(16,5 \%)$ & 182 \\
$21-22$ years old & $67(91,8 \%)$ & $6(8,2 \%)$ & 73 \\
Total & 256 & 44 & 300 \\
\hline
\end{tabular}

Table 3 Characteristics of Subjects with Tension Type Head Based on Gender

\begin{tabular}{lccc} 
& \multicolumn{2}{c}{ Tension-Type Head } & \\
\cline { 2 - 4 } Sex & Yes & No & Total \\
\hline Male & $\mathbf{N}(\%)$ & $17(13,1 \%)$ & 130 \\
Female & $113(86,9 \%)$ & $27(15,9 \%)$ & 170 \\
Total & $143(84,1 \%)$ & 44 & 300 \\
\hline
\end{tabular}

Table 4 Characteristics of Subjects with Tension Type Head Based on Semester Levels

\begin{tabular}{lccc}
\hline & \multicolumn{2}{c}{ Tension-Type Head } & \\
\cline { 2 - 3 } Semester Levels & Yes & No & Total \\
\hline $2^{\text {nd }}$ semester & $81(81 \%)$ & $19(19 \%)$ & 100 \\
$4^{\text {th }}$ semester & $85(85 \%)$ & $25(15 \%)$ & 100 \\
$6^{\text {th }}$ semester & $90(90 \%)$ & $10(10 \%)$ & 100 \\
Total & 256 & 44 & 300 \\
\hline
\end{tabular}


Table 5 Correlation of Anxiety Disorders with Tension Type Head

\begin{tabular}{lcccccc}
\hline & \multicolumn{2}{c}{ Tension-Type Head } & & Total \\
Anxiety Disorders & Yes & No & N (\%) & r & p \\
\cline { 2 - 4 } Yes & $189(94,5 \%)$ & $11(5,5 \%)$ & & $200(100 \%)$ & 0,153 & 0,001 \\
No & $67(67 \%)$ & $33(33 \%)$ & & $100(100 \%)$ & & \\
Total & $256(85,3 \%)$ & $44(14,7 \%)$ & $300(100 \%)$ & & \\
\hline
\end{tabular}

review by Waldie et al. (2015), in most people, TTH first occur before the age of 20 years old and continue to increase until they experience peak prevalence between the ages of 30 and 39 years old. ${ }^{10}$ According to Katsavara et al. (2009) in Waldie et al. (2015), the average population of young adults were preoccupied with their careers and social relationships, so that affecting physical and psychological conditions that increase the risk of TTH. ${ }^{10}$

Based on table 3, the proportion of tension-type headaches is more experienced by men with 113 of 130 people $(86.9 \%)$. The study result was in line with the study conducted by Lampl et al. (2016), the prevalence of men experiencing TTH was $41.6 \%$ compared to women (37.7\%). ${ }^{11}$ In a study by Yadav (2016), the case of TTH between women and men is 5: 4 . This ratio shows that women are a little more often affected by TTH than men. Factors that trigger the case of TTH include stress (mental or physical), irregular eating patterns, consumption of coffee and other caffeine in high doses, dehydration, and inappropriate physical activity. ${ }^{12}$ In this study, men (86.9\%) were slightly more to experience TTH than women (84.1\%), because physical activity carried out by men as research subjects were greater than women. Furthermore, coffee and caffeine are also more frequently consumed by men than women in this study sample.

Based on table 4, the research subjects at the $6^{\text {th }}$ semester had more TTH with 90 out of 100 people (90\%). According to Yadav (2016), the case of TTH is in line with the level of education, where the peak case is found in subjects who have graduated from education in both men (48.5\%) and women (48.9\%). ${ }^{12}$ Accordance with the study conducted by Freitag (2013), subjects in the study who experienced TTH was more common in individuals who had received an education degree. ${ }^{13}$ In this study, subjects at the $6^{\text {th }}$ semester were expected to experience more TTH than subjects at the $2^{\text {nd }}$ and $4^{\text {th }}$ semester because the higher the semester level, the more difficult the material course be learned. Also, subjects in the $6^{\text {th }}$ semester are also required to do the final project of education as thesis, between the materials given daily makes the subjects in this semester has more burden of mind.

A tension-type headache is a primary headache that most often occurs in populations with a prevalence of around $78 \%{ }^{3}$ The case of TTH is influenced by many factors, one of which is anxiety disorders. The proportion of TTH in this study was 85.3\% $(\mathrm{N}=256)$, with the proportion of subjects who are experiencing TTH and also complaining of anxiety disorders at $94.5 \%(\mathrm{~N}=189)$. The value of $\mathrm{p}=0.001$ indicates a significant correlation between the two variables $(p<0.005)$ but with the strength of a weak correlation $(r=0.153)$. A significant statistical result states that the case of anxiety disorders and TTH in medical students can influence each other even though the correlation is weak. The result is supported by several studies regarding the correlation of anxiety disorders and TTH.

The study by Lebedeva et al. (2016) found 154 of 666 (23.1\%) medical students in Russia had anxiety disorders and TTH ( $\mathrm{p}=0.004 ; 95 \%$ CI: 1.2-2.9). However, the association of anxiety disorders with migraines was found to be $27.5 \%(\mathrm{p}<0.001 ; 95 \% \mathrm{CI}$ : $1.5-3.7)$. From these two results, it was found that the correlation of anxiety disorders with migraines was stronger than with TTH. ${ }^{14}$

The study by Lampl et al. (2016) also showed an association between anxiety disorders and tension-type headaches, which were $2.5 \%$ in men $(\mathrm{p}<0.0001)$ and $1.5 \%$ in women $(\mathrm{p}=0.021)$. However, in a study by Lampl et al. (2015), the strength of the correlation between the two variables was weak when compared with the strength of the correlation between anxiety disorders and migraines (4.2\% in men and $2.4 \%$ in women). ${ }^{11} \mathrm{In}$ a study by Zebenholzer et al. (2016), 7.6\% of the research subjects experienced anxiety disorders and TTH, while subjects with anxiety and migraine were $89.1 \% .^{15}$

Subjects with tension-type headaches were found to have more frequent insomnia and fatigue $(p<0.001)$ compared to anxiety disorders ( $\mathrm{p}<0.01) .{ }^{16}$ This is caused by TTH sufferers having low sleep waves and lack of sleep quality which increases the frequency of fatigue during activity and decreases the pain threshold.

In a study by Haque et al. (2012), factors that were thought to exacerbate the case of tension-type headaches, such as anxiety, fatigue, stress, light effects, and sleep disturbances, were investigated and compared to the proportion of TTH. Anxiety and stress factors were normally distributed 
$(\mathrm{p}>0.05)$, while fatigue $(\mathrm{p}<0.05)$, sleep disorders $(\mathrm{p}<0.05)$, and light effects $(\mathrm{p}<0.01)$ were found to have a significant effect on patients TTH. ${ }^{17}$

In the cohort study by Lyngberg et al (2005) in Rains et al (2015), found that sleep disorders are 2.7 times increase the case of a headache (at least 180 times within a year period) in patients with TTH than in who do not have sleep disorders $(\mathrm{OR}=2.7$; 1.1-6.3). An unfavorable prognosis for TTH was also predicted to occur in subjects with lack of sleep $(\mathrm{OR}=1.4 ; 1.1-2.0)$ and subjects with complaints of fatigue $(\mathrm{OR}=2.5 ; 1.3-4.6) .{ }^{18}$

Another factor predicted to worsen the prognosis of TTH is excessive use of drugs. In the drug users, the chronic headache was obtained during follow-up. ${ }^{19}$

Through the results of this study, it was found that medical students at the Medical Faculty of Udayana University had a high case of TTH with comorbid anxiety disorders (94.5\%). However, subjects with TTH but not anxiety disorders were obtained by $67 \%$. The ratio between subjects with anxiety disorders and without anxiety disorders of TTH is 7: 5. The ratio showed no significant difference between subjects with anxiety disorders and without anxiety disorders, so that found a weak correlation between anxiety disorders and TTH. The strength of the weak correlation between anxiety disorders and TTH is probably due to other stronger factors that affecting TTH compared to anxiety disorders, such as fatigue, sleep disorders, stress, and excessive use of drugs..$^{16,17,18}$ Also, based on previous studies, anxiety disorders are more strongly associated with other types of headaches, such as migraines. ${ }^{14,11,15}$

The results of this study indicated that medical students are subjects who had a high risk of a tension-type headache with possible comorbid against anxiety disorders, but these two variables have a weak correlation.

\section{CONCLUSION}

There were more in the age of 21-22 years old $(91.8 \%)$ respondents with a tension-type headache found in this study; male (86.9\%), and in $6^{\text {th }}$ semester $(90 \%)$. The proportion of research subjects who experienced TTH were $85.3 \%$, and those with anxiety disorders were $94.5 \%$ ( 189 of 256 people). $\mathrm{P}=$ $0.001(p<0.005)$ indicates that there is a significant relationship between anxiety disorders with TTH by the strength of the weak correlation $(r=0.153)$.

Medical students are at high risk for suffering tension-type headache requiring adequate prevention and treatment of the factors that affect the TTH, where one of them is anxiety disorders. In addition to anxiety disorders, there are other factors associated with a tension-type headache, and it needs to be further investigated.

\section{REFERENCES}

1. Viona. Nyeri Kepala. Jakarta: Universitas Kristen Krida Wacana. 2012.

2. Lindsay KW. Et al. Headache, neurology and neurosurgery. London: Churchill Livingstone. 2004.

3. Anurogo D. Tension-Type Headache. CDK-214. 2014. 41(3), pp. 186-191.

4. Pluta MR. Tension-Type Headache. The Journal of American Medical Association. 2016. 306(4), p. 450.

5. Ramezani A. Head Pain and Psychiatric Illness: Applying the biopsychosocial model to care. Current Psychiatry. 2015. 14(9), pp. 13-19.

6. Wei CB. Et al. Overlap between headache, depression, and anxiety in general neurological clinics: A cross-sectional study. Chinese Medical Journal. 2016. 129(12).

7. Tabalipa F de O. Prevalence of Anxiety and Depression among Medical Students. 2015. 39(3), pp. 388-394.

8. Ibrahim MB. \& Abdelreheem MH. Alexandria University Faculty of Medicine Prevalence of anxiety and depression among medical and pharmaceutical students in Alexandria. Alexandria Journal of Medicine. Alexandria University Faculty of Medicine. 2015. 51(2), pp. 167-173.

9. Al-jabry NT Et al. Prevalence and Risk Factors of Tension Headache among 3rd Year Female Medical Students at Taibah University in Saudi Arabia. International Journal of Academic Scientific Research. 2015. 3(4), pp. 46-53.

10. Waldie KE. Et al. Tension-Type Headache : A Life-Course Review. Journal of Headache \& Pain Management. 2015. 1(1), pp. 1-9.

11. Lampl C. Et al. Headache, depression and anxiety : associations in the Eurolight project. The Journal of Headache and Pain. 2016. 17(59), pp. 2-9.

12. Yadav P. Prevalence of Tension Type Headache among Young Adults and Their Gender Difference on Percieved Stress Scale: A Comparative Study The International Journal of Indian Psychology, (2016) 4(1), pp. 173-177.

13. Freitag F. Managing and treating tension-type headache. Med Clin North Am. 2013. 97, pp. 281-292.

14. Lebedeva ER., Kobzeva NR. \& Gilev DV Psychosocial factors associated with migraine and tension-type headache in medical students. Cephalalgia. 2016. 0(0), pp. 1-8.

15. Zebenholzer K., Et al. Impact of depression and anxiety on burden and management of episodic and chronic headaches- a cross-sectional multicenter study in eight Austrian headache centers. The Journal of Headache and Pain. 2016. 17(15), 2-4.

16. Engstrøm M. Et al. Sleep quality and arousal in migraine and tension-type headache: the headache-sleep study. Acta Neurologica Scandinavica. 2014. 129, pp. 47-54.

17. Haque B. Et al. Precipitating and relieving factors of migraine versus tension type headache. BMC Neurology. 2012. 12, pp. 2-5.

18. Rains JC., Davis RE., and Smitherman TA. Tension-Type Headache and Sleep. Curr Neurol Neurosci Rep. 2015. 15, pp. 1-9.

19. Probyn K. Et al. Prognostic factors for chronic headache. Neurology. 2017. 89, pp. 1-12.

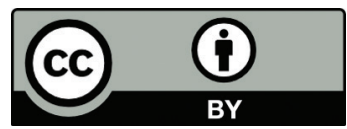

This work is licensed under a Creative Commons Attribution 